\title{
Evolution of Individuality: A Case Study in the Volvocine Green Algae
}

\author{
Erik R. Hanschen, ${ }^{* \dagger \ddagger}$ Dinah R. Davison, ${ }^{* \dagger}$ Zachariah I. Grochau-Wright, ${ }^{\dagger}$ \\ and Richard E. Michod ${ }^{\dagger}$
}

\begin{abstract}
While numerous criteria have been proposed in definitions of biological individuality, it is not clear whether these criteria reflect the evolutionary processes that underlie transitions in individuality. We consider the evolution of individuality during the transition from unicellular to multicellular life. We assume that "individuality" (however it is defined) has changed in the volvocine green algae lineage during the transition from single cells, to simple multicellular colonies with four to one hundred cells, to more complex multicellular organisms with thousands of differentiated cells. We map traits associated with the various proposed individuality criteria onto volvocine algae species thought to be similar to ancestral forms arising during this transition in individuality. We find that the fulfillment of some criteria, such as genetic homogeneity and genetic uniqueness, do not change across species, while traits underpinning other aspects of individuality, including degrees of integration, group-level fitness and adaptation, and group indivisibility, change dramatically. We observe that different kinds of individuals likely exist at different levels of organization (cell and group) in the same species of algae. Future research should focus on the causes and consequences of variation in individuality.
\end{abstract}

$$
\begin{gathered}
\text { Keywords } \\
\text { volvocine algae } \bullet \text { multicellularity } \\
\text { multilevel selection } \bullet \text { individision of labor }
\end{gathered}
$$

\section{Introduction}

All disciplines must define their basic units and core processes. In evolutionary biology, the core process is natural selection and the basic unit of selection and adaptation is the individual. To operationalize the theory of natural selection we must count individuals, as they are the bearers of fitness. While canonical individuals have often been taken to be multicellular organisms

\section{*equal contributors}

${ }^{\dagger}$ Department of Ecology and Evolutionary Biology, University of Arizona, Tucson, AZ 85721, USA †hanschen@email.arizona.edu (corresponding author)

Received 17 January 2017; Accepted 21 February 2017 doi:10.3998/ptb.6959004.0009.003 
(Jeuken 1952; Hull 1976, 1980; Tauber 1991; Pepper and Herron 2008), the hierarchy of life (e.g., simple prokaryotic cells, eukaryotic cells, multicellular organisms, and eusocial groups) shows that new kinds of individuals have evolved (Buss 1987; Maynard Smith 1988; Maynard Smith and Szathmáry 1995; Michod and Roze 1997). A variety of criteria have been used to define biological individuality. Some criteria rely on the presence/absence of a particular property while others advocate an approach that reflects the process of natural selection. The plethora of approaches to classifying individuality has resulted in confusion regarding how to study individuality in a given taxon (Pepper and Herron 2008).

We investigate how the various criteria proposed for delineating individuality map onto a well-studied case of the evolution of multicellular individuality in the volvocine green algae. We assume that "individuality" (however it is defined) has changed in the volvocine algae lineage from being a property of the cell to being a property of the multicellular group. We begin by briefly presenting the various criteria for individuality and some of the issues that can arise in applying them. We then use the volvocine green algae to examine which traits have changed during the evolution of multicellularity and how these traits relate to and satisfy the various criteria used to define individuality (Table 1). We find that the traits associated with some criteria, such as genetic homogeneity and genetic uniqueness, probably do not change much in this lineage, while others change dramatically, including degrees of integration, group-level fitness and adaptation, and group indivisibility. We discuss how differences in the fulfillment of these criteria between genera inform our understanding of individuality and the inherently multi-level nature of the process of natural selection.

\section{Individuality Criteria}

\subsection{Genetic homogeneity}

Genetic homogeneity requires that parts within the individual have the same genotype. For a multicellular organism, this can be achieved via a unicellular reproductive bottleneck (Weismann 1904; Simpson et al. 1957; Dawkins 1982; Crow 1988; Maynard Smith 1988; Grosberg and Strathmann 1998). Genetic homogeneity inhibits the potential for lower-level competition via the reduction of genetic variation amongst cells (Buss 1985, 1987). Issues with this definition arise for example, when mutations occur during development in a multicellular organism. In many plants, somatic mutations accumulate between cell lineages (Whitham and Slobodchikoff 1981). Somatic mutations have also been reported in fungi (Peabody et al. 2000; Stenlid 2000), red algae (Santelices and Varela 1993; Meneses et al. 1999; Santelices et al. 1999), invertebrates (Rinkevich and Weissman 1987; Barki et al. 2002; Sommerfeldt et al. 2003), and vertebrates (De 2011).

\subsection{Genetic uniqueness}

Genetic uniqueness is the possession of a genotype different from that of other individuals and is primarily conferred by sexual reproduction. The amount of genetic uniqueness created by sex will depend on the mating system and degree of inbreeding. This definition clearly distinguishes an individual from other individuals of the same species (Weismann 1904; Huxley 1912; Santelices 1999) and facilitates selection amongst colonies (Buss 1985). In this view, organisms or ramets produced asexually from the same clone are not individuals, but instead represent the growth or expansion of a single biological individual, the genet. This definition is difficult to relate to facultatively sexual species (where two ramets may or may not be different individuals 


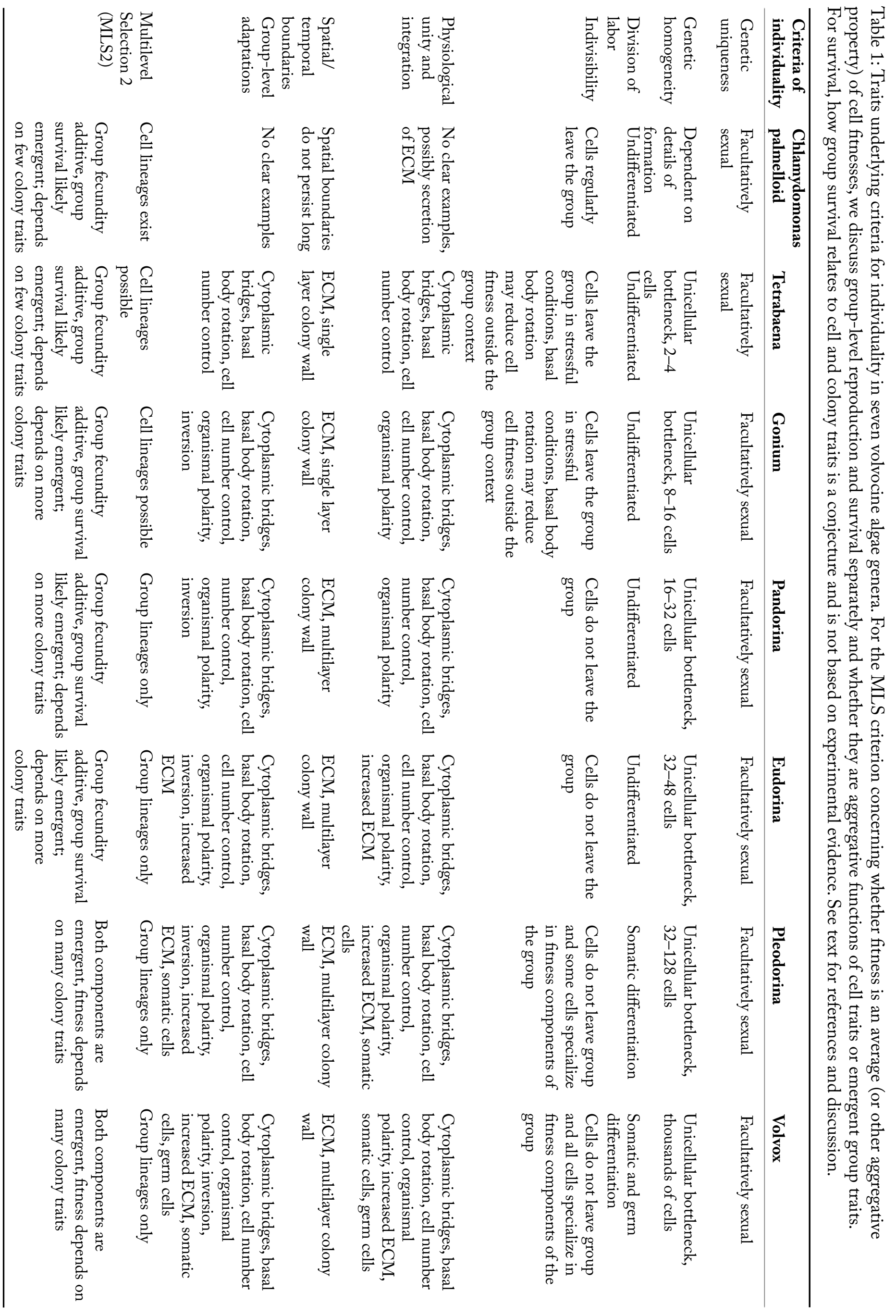


depending on which genet they belong to) (Huxley 1912; Janzen 1977). The example of genetic heterogeneity accumulating through somatic mutations raises issues with this definition as well (Stoner et al. 1999).

\subsection{Reproductive division of labor}

Another criterion is reproductive division of labor (Weismann 1885; Buss 1987), in which lowerlevel units specialize on the basic fitness components of the group (Maynard Smith and Szathmáry 1995; Michod 2005, 2006, 2007). Reproductive division of labor promotes cooperation and inhibits conflict amongst lower-level entities. By specializing on survival or reproduction of the group, lower-level units, such as cells, give up their own fitness were they to live outside of the context of the group (Michod 2007). At the same time, fitness emerges at the group level and a change in the Darwinian unit of fitness and adaptation from one level to another has occurred. In the evolution of multicellularity, division of labor often takes the form of germ-soma differentiation, in which cells specialize in either group survival or group reproduction. The sequestration of a germ line also reduces the per-generation mutation rate (Simpson et al. 1957; Buss 1987; Michod 1996), thereby reducing the potential for cell-level conflict. Due to the ubiquity and importance of germ-soma division of labor (Simpson 2012), some multicellular groups without this trait have been considered to lack individuality (Godfrey-Smith 2009). Reproductive division of labor simultaneously increases group-level fitness and decouples the group-level fitness from the average of lower-level fitnesses (Michod 2006; Michod et al. 2006; Hanschen et al. 2015). While the evolution of division of labor is an especially clear example of how fitness decoupling may occur, it is not the only means. Any trait that is costly at the lower level but beneficial at the group level enhances the fitness of the group at the expense of lower-level fitness and may therefore contribute to fitness decoupling and the emergence of indivisibility of the group. In addition, traits that evolve in the context of the group may no longer be optimal were cells to leave the group (Shelton and Michod 2014). This context-dependent evolution increases the fitness of the group and decreases the fitness of cells were they to leave the group.

\subsection{Indivisibility}

The Latin root of the word "individual" means indivisible (Table 1). Under this criterion, an individual cannot be divided into smaller units that still maintain the properties of the whole (Michod 1999, 2007). Indivisibility facilitates selection at the group level and inhibits lowerlevel selection. Groups that are indivisible can be subjected to novel and different selection pressures. If a group is divisible, lower-level units could leave the group and form lineages, allowing for heritable variation in fitness and selection at the cell level. Fitness decoupling, discussed above in regards to division of labor, also leads to indivisibility as cells cannot well survive and reproduce outside of the group (Michod 2007). A group is indivisible if lower-level units cannot leave the group, potentially because of a colony boundary. Indivisibility may also arise when cells possess properties in the context of the group that would make them less fit were they to leave the group (Shelton and Michod 2014).

\subsection{Autonomy and physiological unity}

Huxley (1932) considered individuality to be characterized by autonomy and physiological unity (Table 1), which imply that the individual interacts as a whole with the external environment. Integration of lower-level component parts is closely related to physiological unity (Sober and Wilson 1994; Michod 2007). The definition of an individual as possessing physiological unity 
and integration is meant to reflect the interaction between parts of an individual, increasing the likelihood that heritable variation in fitness will exist amongst groups and not the parts (Clarke 2013). This interaction among parts can be thought of as affecting the fitness of the whole. Identifying specific traits and characters which constitute physiological unity and integration can be challenging, especially as parts of an individual may demonstrate substantial internal unity and integration themselves (Clarke 2010). For example, a cell of a multicellular organism displays unity and integration between its sub-cellular component parts (Clarke 2010). Similarly, the rapid and high level of coordination amongst European starlings doesn't necessarily make a murmuration an individual (Sterelny and Griffiths 1999).

\subsection{Spatial and temporal boundaries}

Other individuality criteria focus on the discrete and integrated nature of individuals (Table 1). Individuals have clear spatial and temporal boundaries and are localized in both time and space (Hull 1976, 1980; Buss 1987; Mishler and Brandon 1987). The criterion of being spatiotemporally localized emphasizes that selection acts upon discrete units (Hull 1976) and the spatial/temporal organization of integrated parts which comprise that individual (Hull 1980). Spatial/temporal boundaries increase the likelihood that heritable variation in fitness exists between groups, with selection acting on these autonomous groups (Clarke 2013).

\subsection{Group-level adaptations}

The presence of group-level adaptations is another criterion for individuality (Vrba 1984; Folse and Roughgarden 2010; Shelton and Michod 2014).This criterion captures the expected outcome of Darwinian evolution at the group level (Lewontin 1970). The criterion of grouplevel adaptations specifically excludes cross-level byproducts, which occur when lower-level and group-level traits covary resulting in apparent selection at the group level (Okasha 2006). Nevertheless, it remains a challenge to identify what is an adaptation at the group level (Clarke 2010). Determining whether group properties are aggregative or emergent properties of cells and understanding the relationship between group-level traits and fitness at the cell and group levels may help identify group-level adaptations (Damuth and Heisler 1988; Lloyd and Gould 1993; Wimsatt 1997). Shelton and Michod (2014) have proposed testable predictions, based on an explicit mathematical model, which help to determine whether traits are group-level adaptations including strong group-level fitness effects.

\subsection{Multilevel selection}

Finally, the criteria used to understand different paradigm cases of multilevel selection (so-called MLS1 and MLS2 [Heisler and Damuth 1987; Damuth and Heisler 1988]) have been used to understand whether individuality exists at the group or the lower level (Okasha 2006; Shelton and Michod 2009). Do the groups themselves form lineages or are lineages just properties of the units that make up the group? How is group fitness composed out of cell fitness? Is the fitness of the group an average or aggregate property of the fitnesses of the cells comprising the group or is group fitness a non-linear or even discontinuous function of cell properties? Okasha (2006) argues the transition from MLS1 to MLS2 may be thought of as a defining property of individuality at the group level. Initially group-level fitness is defined as the average of lowerlevel fitness (MLS1) as in the trait-group model of Wilson (1975). As the groups become more integrated, group lineages arise and selection transitions from MLS1 to MLS2 (Okasha 2006), 
and individuality emerges at the group level. In this view, once MLS2 is relevant, groups form lineages and group fitness is a non-aggregative function of cell properties.

\section{The Volvocine Green Algae}

Multicellularity has evolved at least 25 times across the tree of life including in bacteria, archaea, and eukaryotes (Bonner 1998; Grosberg and Strathmann 2007). In the Chlorophyte green algae, one finds the volvocine algae, a particularly tractable model system for studying the evolution of multicellularity (Figure 1). First described by Antony van Leeuwenhoek (1700), the volvocine green algae are an informal clade of approximately 90 species that includes unicellular, undifferentiated multicellular, and differentiated multicellular species. The volvocine algae include numerous phenotypes along this gradient of complexity, making them an ideal model system for studying the evolution of multicellular individuality.

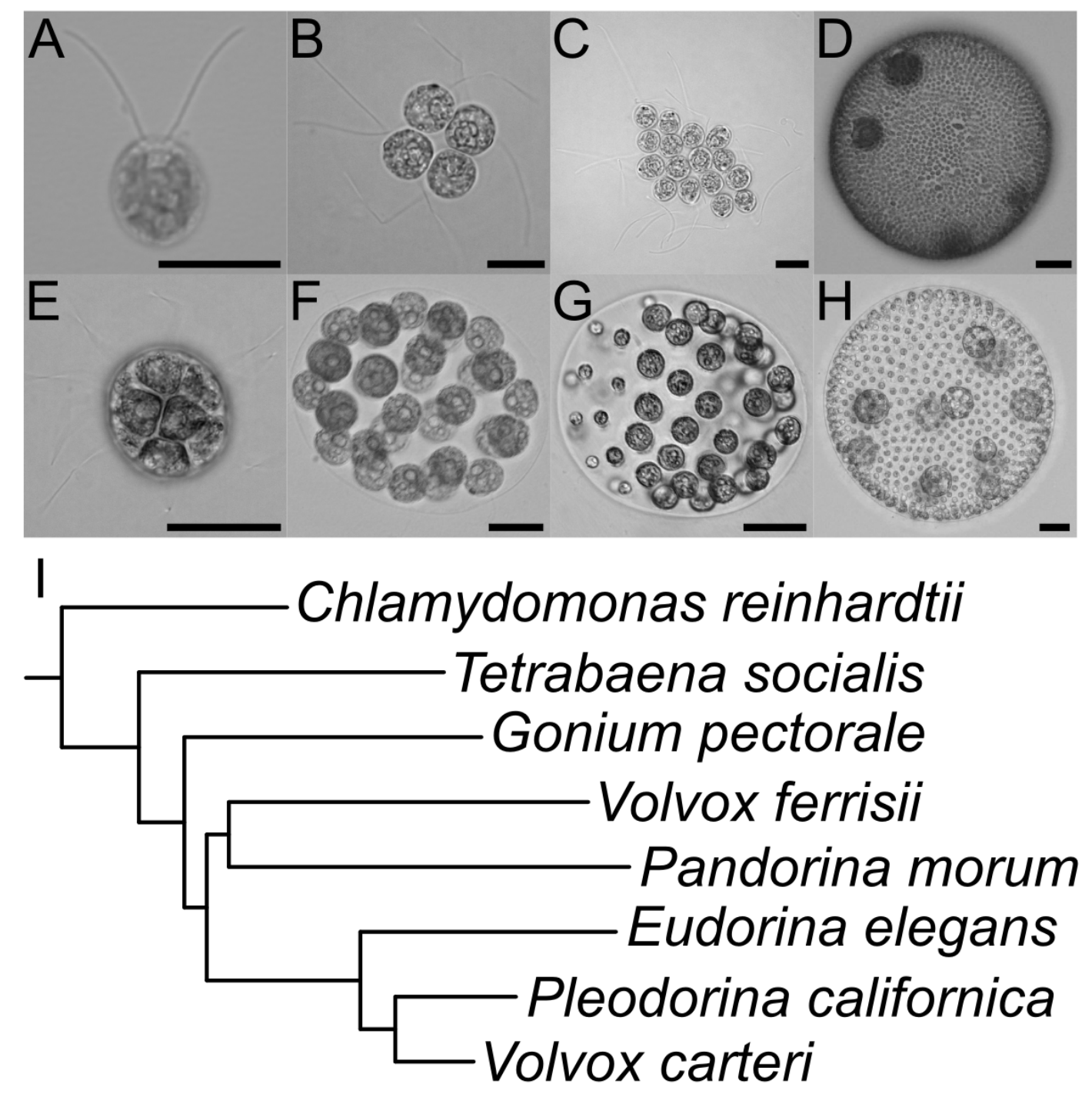

Figure 1: Micrographs of select volvocine genera (same order as in I.); A. Chlamydomonas (scale bar, $10 \mu \mathrm{m})$, B. Tetrabaena $(10 \mu \mathrm{m})$, C. Gonium $(10 \mu \mathrm{m})$, D. Volvox ferrisii $(50 \mu \mathrm{m})$, E. Pandorina $(25 \mu \mathrm{m})$, F. Eudorina $(25 \mu \mathrm{m})$, G. Pleodorina $(50 \mu \mathrm{m})$, H. Volvox carteri $(50 \mu \mathrm{m})$. I. Phylogenetic tree of select volvocine species. 


\subsection{Overview of the volvocine green algae}

The volvocine green algae (Figure 1) live in still bodies of freshwater such as puddles and ponds, germinating from desiccation-resistant diploid spores as conditions allow (Pocock 1933a,b). In permissive ecological conditions, volvocine algae germinate to form haploid colonies which reproduce asexually. When ecological conditions deteriorate, including due to nitrogen deprivation (Sager and Granick 1954; Kates and Jones 1964; Harris 2009) and heat shock (Kirk and Kirk 1986; Kirk 1998), colonies sexually differentiate and produce desiccation-resistant diploid spores (Janet 1912). They are photosynthetic but negatively buoyant, and thus need to maintain their position in the water column through flagellated motility. Motility plays a critical role in their ecology; some species can perform daily migrations through the water column, photosynthesizing at the water's surface during the day and migrating to the bottom of the pond, presumably in search of phosphorus and other nutrients, at night (Sommer and Maciej Gliwicz 1986). Flagellar action also serves to mix the surrounding water to aid in the uptake of nutrients and removal of waste products (Short et al. 2006; Solari et al. 2006a).

Species are globally distributed (Smith 1944; Coleman 2012) and range in size and complexity from the unicellular Chlamydomonas reinhardtii to undifferentiated species of four (e.g., Tetrabaena socialis), eight (e.g., Gonium pectorale), sixteen (e.g., Pandorina morum), or thirty-two cells (e.g., Eudorina elegans), to soma differentiated species (e.g., Pleodorina californica), to the germ-soma differentiated Volvox carteri with thousands of cells (Figure 1). The cells of undifferentiated species resemble Chlamydomonas, somatic cells in Pleodorina and Volvox resemble small Chlamydomonas cells, and germ cells in Volvox resemble Chlamydomonas but are much larger and not flagellated (Figure 1). These extant species, with diverse levels of complexity are hypothesized to be similar to ancestors during the evolutionary transition from unicellular to multicellular individuals. The volvocine algae do not have a multicellular ancestor and have evolved undifferentiated multicellularity once (Herron and Michod 2008; Leliaert et al. 2012). Their relatively recent radiation, approximately 200 million years ago, facilitates the identification of genetic and phenotypic changes associated with the evolution of multicellularity (Kirk 2005; Herron et al. 2009; Prochnik et al. 2010; Hanschen et al. 2016).

\subsection{Individuality criteria applied to the volvocine algae}

We now discuss how the previously introduced individuality criteria are satisfied throughout the volvocine algae. Regarding genetic homogeneity, mutations may arise in cell lineages during development, but given the relatively small number of rounds of cell division (approximately twelve in the case of Volvox carteri) compared to other multicellular taxa such as plants or animals, colony-level genetic homogeneity is probably high throughout this lineage. Still the opportunity for within colony variation and genetic conflict should correlate with the number of rounds of cell division and colony size (Table 1). All things being equal, genetic homogeneity (and hence individuality) should decrease with colony size. Regarding genetic uniqueness, all volvocine algae are facultatively sexual, so barring mutation, asexual clones arising in a lineage from a single germinated spore are not genetically unique. The degree of genetic uniqueness for colonies derived from different germinated spores will depend on the mating system, effective population size, and degree of inbreeding. Unfortunately, little is known about these factors in the volvocine algae. Regarding spatial/temporal boundaries, except for differences in how the colony wall is formed in these species (Kirk 2005), the volvocine algae have similar spatial/temporal boundaries, suggesting this criterion remains relatively constant in this lineage (Table 1). However, as discussed below, the elaboration of the colony wall may have implications for the indivisibility criterion and whether cells can leave the group. 
We turn to the remaining criteria (physiological unity and integration, indivisibility, grouplevel adaptations, division of labor, and MLS2) and will discuss them one genus at a time. We have selected genera to represent observed variation in traits that appear most relevant to the evolution of individuality. Other genera exist but, with the exception of Astrephomene (which has cellular differentiation but not inversion [Iyengar and Desikachary 1981; Nozaki 1983]), they do not display different or unique combinations of the traits we discuss here. We present these genera in order of increasing body size, though some of the traits we discuss here have evolved multiple times in the volvocine green algae (Herron and Michod 2008). Based on the reconstructed evolutionary history in Herron and Michod (2008), it is hypothesized that many of these genera are similar to ancestral populations, as least with respect to the major traits related to the evolution of multicellularity as identified by Kirk (2005).

\subsubsection{Chlamydomonas}

Unicellular Chlamydomonas reinhardtii (Figure 1) forms multicellular clusters under certain conditions. One form of multicellular clusters, non-motile palmelloid clusters, are thought to form through the adhesion of daughter cells via an extracellular matrix or by failure of daughter cells to hatch out of the mother cell wall (Harris 2009; Khona et al. 2016). These clusters typically include 2, 4, 8, or 16 cells. Palmelloid clusters can facultatively form as a result of treatment inhibiting daughter cell hatching (e.g., calcium deprivation, chelating agents, high salt concentrations) and treatment resulting in cell wall aberrations (Iwasa and Murakami 1968; Nakamura et al. 1975, 1978; Harris 2009; Khona et al. 2016). More recently, multicellular clusters of Chlamydomonas have been used to investigate ecological and evolutionary questions. Of course, caution must be taken when using laboratory experiments to inform how selection operates on Chlamydomonas in nature. Lurling and Beekman (2006) demonstrated how palmelloid clusters facultatively form as a result of rotifer predator presence. These palmelloid clusters varied from 2 to 10+ cells and appeared to form as a result of adhesion of daughter cells via an extracellular matrix. Becks et al. (2010) used a Brachionus rotifer predator, palmelloid Chlamydomonas (evolved through six months of exposure to Brachionus), and unicellular Chlamydomonas to investigate community dynamics. Palmelloid clusters varied in size from 2 to $140+$ cells held together by a thin extracellular matrix. Cells in these palmelloid clusters had a significant reduction in growth rate and a significant increase in predator survivorship, suggesting a trade-off between survival and reproduction when cells are in a palmelloid cluster. Ratcliff et al. (2013) experimentally evolved obligate multicellular Chlamydomonas clusters using centrifugation to select on cluster size. Evolved multicellular Chlamydomonas clusters contained over 100 cells descended from a single cell. Clusters were held together through secretion of an extracellular matrix (Ratcliff et al. 2013). Sathe and Durand (2015) used a Euglenoid predator (Peranema trichophorum) to demonstrate Chlamydomonas can aggregate (in contrast to forming clusters through daughter cells failing to leave the mother wall) in clusters of 10-100,000 cells. Using Chlamydomonas reinhardtii, C. moewusii, and C. debaryana, the formation of multi-species aggregations of approximately 100 cells was observed.

Multicellular Chlamydomonas clusters have clear spatial boundaries, but as cells are able to leave palmelloid clusters (Khona et al. 2016) we do not consider them indivisible. Cell clusters may form via aggregation between separate genetic strains, suggesting Chlamydomonas clusters are not always genetically homogenous (Sathe and Durand 2015); however, in the other studies discussed above, the clusters are considered to be clonally formed and genetically homogenous. Germ-soma division of labor is not present. The case of palmelloid clusters illustrates the challenges involved in distinguishing the level of selection leading to increased physiological unity 
and the presence of true group adaptations (see Clarke 2010, 2013). In our opinion, there are no clear examples of physiological unity or group-level adaptations in palmelloid clusters, although secretion of extracellular matrix upon which cluster formation is based is a potential candidate. Alternatively, the secretion of extracellular matrix may be a cell-level adaptation which increases the inclusive fitness of secreting cells. Shelton and Michod (2014) analyzed a model of simple clusters of genetically identical cells as a way to understand when group-level adaptations emerge. The conditions under which group adaptations emerge depend on how strongly group membership affects life history variables such as mortality and growth. While the beneficial effect of group membership on lowering predation rates is consistent with group adaptations being present in Chlamydomonas palmelloid clusters (Shelton and Michod 2014), it is not sufficient to clearly demonstrate their presence. The example of palmelloid Chlamydomonas serves as a null comparison for the undifferentiated colonial species in which group-level adaptation and integration are clearly present.

\subsubsection{Tetrabaena}

One of the simplest and smallest colonial volvocine algae, Tetrabaena socialis, consists of four undifferentiated Chlamydomonas-like cells (Figure 1, [Janet 1912]). During reproduction, each cell in a Tetrabaena colony undergoes two rounds of cell division, producing a four-celled colony. These cells are attached through cytoplasmic bridges which result from incomplete cytokinesis (Arakaki et al. 2013); these bridges likely serve to keep the cells in the group. Integration is enhanced by the existence of rotational asymmetry in the arrangement and rotation of basal bodies (Table 1). These basal bodies connect flagella to the cell wall, allowing for flagellar beating. Rotational asymmetry is unique and universal (in all species where it has been studied) to colonial/multicellular species (Kirk 2005; Arakaki et al. 2013), suggesting that this rotation plays an important role in colonial motility and thus may be considered a group-level adaptation. Finally, the ability to reproduce a four-celled colony (in contrast to a single Chlamydomonas-like cell that can grow and divide many more times) indicates that the number of cells in a colony is genetically modulated in Tetrabaena (Kirk 2005; Arakaki et al. 2013), again, demonstrating the presence of group-level adaptations (Shelton and Michod 2014). However, Tetrabaena does not fulfill other criteria of individuality such as germ-soma division of labor (Table 1) and indivisibility. Tetrabaena colonies break apart during conditions of stress (Harper 1912; Starr 1955) and so the group is divisible in the sense that cells are not completely committed to group living. However, basal body rotation may negatively affect swimming ability outside the context of the group; thus, Tetrabaena has a degree of indivisibility in the sense that it has group level adaptations that may reduce cell fitness outside of the context of a group.

Turning to the MLS criteria, we find that lineages exist at the group level, but may also exist at the cell level when cells leave the group. To understand how group fitness relates to cell fitness and cell properties, we consider each component of fitness (reproduction and survival). In Tetrabaena, as all cells produce a single daughter colony, the fecundity of the group is the sum of cell fecundity. Survival of the group is more complicated and difficult to relate to cell properties. Components of survivorship, such as predation resistance (Boraas et al. 1998), swimming speed (Solari et al. 2006b), and flagellar mixing of the environment (Solari et al. 2006a), may be aggregative properties of cells and may depend on group properties such as cell number. For example, flagellar force of the group (important for both swimming and mixing of the surrounding microenvironment) could be construed to be an aggregative property generated by cells. Likewise, group size (important for predation resistance) is likely an aggregative function of cell size but requires reproducing the number of cells in the group, which is a group trait. This 
group trait likely depends on cell traits such as cell growth rate and cell size at which mitotic divisions commence. Ecologically, the predation resistance of the group could be a step function of cell number (Boraas et al. 1998; Kirk 1998), if the size of the group is above a certain threshold, groups could have high survival, while if the size of the group is below the threshold, the group may have little survivorship. Solitary cells, likely below any size threshold (Kirk 1998), might have little or no survivorship. Thus, the survival of the group (and consequently fitness, the product of survival and reproduction) may not be the average of cell-level fitnesses (Okasha 2006; Shelton and Michod 2009). Increased swimming speed and flagellar mixing of the environment (Solari et al. 2006a,b) also have complex relationships to group survivorship, and may not affect group survivorship until larger colony sizes evolve. Since group-level fitness is sensitive to changes in cell number and organization, group-level fitness is likely emergent (Wimsatt 1997).

In Table 1, we assume that survivorship starts out aggregative and depends on few colony traits. As colonies get larger and more morphologically complex, survivorship is less likely to be an aggregative property of cell properties; simultaneously, the number of group traits affecting survivorship increases. When group traits are no longer aggregative functions of cell traits we refer to them as emergent in Table 1.

\subsubsection{Gonium}

Gonium pectorale is a small colonial species in the Goniaceae family consisting of a plate of 432 Chlamydomonas-like cells (Figure 1). Like Tetrabaena, Gonium develops from a unicellular bottleneck without division of labor; all cells reproduce with no differential investment at the cell level in group survival or reproduction (Table 1). However, Gonium has several traits which satisfy individuality criteria not satisfied in Tetrabaena. First, development in Gonium includes inversion. A Gonium embryo is initially shaped like a shallow bowl, with the flagella pointed in towards the center of the bowl. During development, the colony inverts, reversing the curvature of the colony, so that flagella point outward (Stein 1965). Second, Gonium has a centerperipheral axis in which cells differ in their flagellar orientation (Gerisch 1959). Third, Gonium shares many genomic modifications with germ-soma differentiated Volvox including expanded cyclin D genes (genes which regulate the cell cycle) and structural modifications to retinoblastoma $(R B)$, a cell cycle regulation gene (Hanschen et al. 2016). Given that the modifications to $R B$ cause cell colonies to form and that similar expansions of cyclin $\mathrm{D}$ genes exist in other multicellular taxa, these changes are likely group-level adaptations (Hanschen et al. 2016). As with Tetrabaena, Gonium colonies break apart into smaller units composed of one or more cells in times of stress (Harper 1912). These smaller units can survive and reproduce (personal observation), raising the question as to whether Gonium colonies lack indivisibility. As with Tetrabaena, the fecundity of the group is the sum of the fecundity of the cells, while the survivorship of the group may or may not be an additive property of cell survivorship traits. Lineages typically exist at the group-level except when cells leave the group (Table 1).

\subsubsection{Pandorina}

Pandorina morum (Figure 1) consists of 8-16 cells and repeats many of the points already made, except Pandorina is spherical and has a novel trait potentially relevant to individuality not found in Tetrabaena or Gonium: a multilayer colony boundary. As far as we are aware (and we have tried growing them under stress), there are no reports of Pandorina (or any larger volvocine species) dissociating into single cells under stress. Pandorina appears to be committed to group living as cells do not leave the group (Table 1), which is likely the consequence of a multilayer 
colony wall (Fulton 1978; Kirk 2005). This more complex colony wall is shared with larger species, which are also committed to group living.

\subsubsection{Eudorina}

Species of the genus Eudorina form spherical colonies of 32 to 64 cells (Figure 1) that are similar to Pandorina and repeat many of the points made so far with the exception that Eudorina has an expanded extracellular matrix (ECM) (Conrad 1913; Goldstein 1964; Kirk 2005) made of glycoproteins secreted by the cells (Hallmann 2006). The ECM is composed largely of secreted glycoproteins whose production likely imposes a metabolic cost on the cells, which secrete the ECM (Sumper and Hallmann 1998). This cost is likely overcome by key group-level benefits which may include protection against the external environment (Gerhart and Kirschner 1997) and nutrient storage (Bell 1985; Koufopanou and Bell 1993). The ECM is a shared resource that each cell contributes to, providing an environment in which cheaters, which benefit from the ECM but do not directly contribute to it, could flourish (Herron and Michod 2008). The ECM is a group-level adaptation that likely imposes costs at the level of the individual cell.

\subsubsection{Pleodorina}

The genus Pleodorina forms spherical colonies with 32-128 cells (Figure 1), and meets many of the same criteria as Eudorina, with the important novelty that $20-50 \%$ of these cells are terminally differentiated, non-reproductive, somatic cells located in the anterior hemisphere (Shaw 1894; Nozaki et al. 2006). These somatic cells indicate division of labor involving reproductive altruism is present in Pleodorina (Table 1). The rest of the cells in the colony are Chlamydomonaslike, general-purpose, flagellated cells contributing to both survival (flagellar action) and reproduction. Only the somatic cells are specialized in these species, which are specialized in survival and give up reproduction. The fitness costs of reproductive altruism incurred by somatic cells are compensated for by greater group-level benefits that are brought about by specialized somatic cells such as increased colony motility (Solari et al. 2006b). Cellular differentiation results in differences in cell-level fecundity, some cells do not reproduce at all and have zero fecundity. This means that group-level fitness is clearly not the average of cell-level fitnesses; thus grouplevel fitness is strongly decoupled from cell-level fitness (Table 1). The colony is indivisible in the sense that, if a colony were broken up, the somatic cells could not produce offspring.

\subsubsection{Volvox}

Volvox is a polyphyletic genus and member species fulfill nearly all the individuality criteria discussed (Table 1). Volvox is indivisible and has complete germ-soma division of labor. For example, Volvox carteri contains approximately 12 reproductive germ cells, which do not develop flagella, and approximately 2,000 somatic cells, which cannot reproduce but instead specialize in motility via flagellar action. Therefore both somatic and germ cells are specialized in either group-level survival or group-level reproduction. Volvox species have clear group-level adaptations such as greatly expanded ECM (Powers 1908; Starr 1969, 1970); greater than 99\% of the volume of a Volvox colony is cell-secreted ECM (Hallmann 2003). Some species of Volvox have 50,000 cells and a corresponding increase in number of rounds of cell division, and hence, more opportunities for mutations to arise. Volvox species are therefore predicted to be marginally less genetically homogeneous than smaller species, all other factors being equal.

Volvox species display similar phenotypic characteristics with one key difference: the timing of reproductive cell flagellar loss. In the group of Volvox which includes Volvox ferrisii (represent- 
ing an independent evolution of the Volvox body plan from Volvox carteri; (Figure 1, [Herron et al. 2010]), reproductive cells are not specialized as they retain their flagella early in development (Pocock 1933b; Isaka et al. 2012). Could these Volvox species be considered to be less integrated than Volvox carteri because they do not have specialized germ cells? On the other hand, species such as $V$.ferrisii maintain cytoplasmic bridges between reproductive and somatic cells throughout their life cycle (Smith 1944; Isaka et al. 2012). Conversely, cytoplasmic bridges in $V$. carteri are broken down at the end of embryogenesis (Kirk 1998). While the function of these cytoplasmic bridges is unknown, they may serve to transport nutrients and waste or facilitate intercellular communication. If so, it could be argued that $V$. ferrisii is more integrated than $V$. carteri (Godfrey-Smith 2011). If traits such as the maintenance of cytoplasmic bridges or flagella in reproductive cells affect integration, or could be considered group-level adaptations, they affect the level of individuality in Volvox species. However, the differences of flagellar loss in reproductive cells and cytoplasmic bridges may be negligible compared to the morphological similarities they share.

\section{Discussion}

\subsection{Summary of individuality in the volvocine algae}

Our review of how various criteria for individuality relate to the volvocine algae shows that criteria differ in how they are fulfilled across genera that are thought to span the divide between unicellular and multicellular individuals. Some criteria, such as genetic uniqueness and genetic homogeneity, do not appear to change substantially in the extent to which they are satisfied from Chlamydomonas palmelloid clusters to Volvox. For other criteria, such as physiological unity and the presence of group-level adaptations, there is a gradient across genera in the extent to which the criteria are satisfied. Traits fulfilling group-level adaptations and physiological unity and integration criteria appear to change concurrently across the volvocine algae, as most of the traits that are possible group-level adaptations also promote physiological unity and integration. In contrast, the traits fulfilling other criteria do not change concurrently; for example, the pattern of gradual change in the traits underlying physiological unity and integration is very different from the step-like evolution in division of labor. Criteria such as indivisibility, MLS2, and division of labor are satisfied at different times and stages during the evolution of multicellularity in the volvocine green algae. These three criteria critically inform how selection likely acts at different levels in the different genera and so it may be expected that their underlying traits would change as the unit of selection changes levels. Indivisibility and division of labor reduce the potential for cell-level conflict and selection while MLS2 reflects how selection operates at both levels in the process of reducing the capacity for selection at the lower level, and enhancing selection at the higher level.

Based on the differences in how selection likely acts in different volvocine genera, we identify three types of volvocine multicellular individuals: Tetrabaena and Gonium, where selection can act on both cells and colonies; Pandorina and Eudorina, where selection acts on colonies that lack the mechanisms seen in other taxa that promote cell-level cooperation and inhibit the potential for cell-level conflict; and Pleodorina and Volvox, where selection clearly operates at the colony level and mechanisms which reduce the potential for cell-level conflict exist. The notion of multiple kinds of multicellular individuals is not novel (Santelices 1999) but our approach to delineating different types of individuality is.

Many definitions of individuality focus upon traits which reduce the possibility of withingroup conflict and selection at the lower level (Maynard Smith and Szathmáry 1995; Michod 
1999; Gardner and Grafen 2009). Our analysis acknowledges the context-dependency and plasticity of individuality. For example, under certain conditions, Gonium multicellular groups reproduce as Darwinian individuals. Yet, when environmental conditions change, the grouplevel individual dies and selection operates on cell-level organisms. This represents a temporary shift from MLS2 (group lineages) to MLS1 (cell lineages). When conditions change again, these cells form multicellular organisms and selection again operates at the level of the group (MLS2). As reflected by the changes in Darwinian properties at different levels in different conditions, the levels at which selection acts can change temporally. Moreover, fitness interests between levels may not be aligned. If an organism lacks mechanisms to sufficiently suppress lower-level conflict, selection acting at one level may interfere with selection acting at another level. Alternatively, fitness interests across levels could be aligned. For example, imagine a mutation which increases the strength of flagella, thus increasing swimming speed and both cell-level and group-level fitness.

\subsection{A multidimensional perspective on individuality}

The level of attention in the literature dedicated to the concept of individuality is born out of necessity - in order to measure fitness and changing frequencies, researchers need to count individuals. To this end, many researchers have proposed a single criteria whose fulfillment is purportedly both necessary and sufficient for individuality (but see Santelices 1999; Pepper and Herron 2008; Clarke 2011, 2013), implying that individuality is a dichotomy and individuals are considered equivalent so long as the required criterion is present. Consistent with this interpretation, individuality is often thought to be present at a single hierarchical level at a time (Dawkins 1982; Maynard Smith 1988; Michod 1999; Gardner and Grafen 2009). Other researchers argue that individuality is not a dichotomy and that there are multiple different kinds of non-equivalent individuals based on variation in genetic uniqueness, genetic homogeneity, and autonomy/physiological unity (Santelices 1999). Queller and Strassmann (2009) compared species based on qualitative differences in the extent of cooperation and conflict, and suggested that continuous variation in individuality exists. Clarke (2013) proposed that definitions of individuality should not be mechanism-specific but should instead reflect both the suppression of selection acting at the lower level and the enhancement of selection acting at the group level, also suggesting group-level individuality may exist in degrees, the extent to which selection can act on group-level units.

A dichotomous formulation of individuality, in which individuality is only present at a single level and all multicellular individuals are conceptually equivalent, is not supported by our analysis and ignores the possibility of different kinds of individuals co-occurring in the same species. The presence of genetic homogeneity in Chlamydomonas clusters depends on the details of cluster formation. Similarly, the temporal variability of cell lineage formation in species such as Tetrabaena and Gonium and the environmentally determined, intermittent occurrence of sexual reproduction in all volvocine species demonstrates that the level and kind of individuality can change across time and space and can be dependent on the environmental context.

The context-dependency of individuality is not restricted to the volvocine algae. For instance, black spruce (Picea mariana) reproduce both sexually from seeds and asexually via clonal propagation (Legere and Payette 1981). On flat terrain at low elevations, sexual reproduction prevails and every ramet represents a unique genet. However, on subalpine slopes asexual reproduction is more common, and ramets do not represent a unique genet (Viktora et al. 2011). In this case, selection is likely operating both between genets and between ramets. Both ramet and genet are individuals, the genets composed of ramets, and individuality depends on envi- 
ronmental context. Similarly, when cancer develops within a canonical multicellular organism, selection is occurring between multicellular organisms but also within a multicellular organism, between cell lineages (Aktipis et al. 2015). Individuality resides at both the level of cell lineages and the multicellular organism, though only when mutation causes cancerous cell lineages to arise. Lastly, in the example of somatic mutation accumulation along a tree branch, genetic variation between branches could result in increased fruit production (increased reproduction) on one branch, beneficial at both the lower (branch) and higher (tree) levels (Whitham and Slobodchikoff 1981; Pineda-Krch and Lehtilä 2004). In this example, both the tree and tree branches are considered to be simultaneous Darwinian individuals.

While individuality is often assumed to be constant across members of a given species, the context-dependency of individuality should be considered and the evolutionary consequences investigated. We suggest researchers embrace a multidimensional approach based on multiple individuality criteria to determine the kinds of individuality present in their system and how selection may be affected. This approach may provide insight into individuality in taxa of interest, as well as how evolution is subsequently impacted. Our approach has utilized a multiplicity of individuality criteria. Mechanistic, trait-based definitions of individuality were critical to inform phenomenological, selection-based definitions of individuality, providing insight to how selection might be acting in the volvocine algae. This multidimensional approach to individuality, composed of trait-based definitions, selection-based definitions, and ecological context, may be informative in future research, particularly in the context of comparative studies.

This multidimensional approach may be fruitful when applied to the evolution of individuality during the evolution of multicellularity in other lineages or other evolutionary transitions such as the evolution of eukaryotes or eusociality. This would entail determining which individuality criteria participating taxa fulfill, as was carried out here with the volvocine algae. As appropriate, the ecological context affecting individuality needs to be taken into account. This mapping can then allow researchers to ask questions about individuality, macroevolutionary trends and patterns, and the capacity to respond to selection. This approach may be fruitful for understanding how different kinds of individuals across the tree of life differ in their evolutionary dynamics, how independent evolutions of one kind of individuality are similar, and how transitions between different levels of individuality are similar.

\section{Conclusions}

Our approach in this paper is to understand individuality by examining how traits that have changed during the evolution of multicellularity in the volvocine green algae relate to the various individuality criteria proposed in the literature. We find that the evolution of multicellular individuality from unicellular ancestors in the volvocine green algae likely involves minor changes in genetic homogeneity, genetic uniqueness, and spatial/temporal boundaries. While necessary for the initiation of group-level selection and evolution, these criteria do not appear to change substantially in the extent they are satisfied during the evolution of individuality in this lineage. Other individuality criteria, including division of labor, indivisibility, and the presence of multilevel selection, vary dramatically in how they are fulfilled. Examining these criteria in the context of ecology suggests three kinds of multicellular individuals: uncommitted multicellular individuals (Tetrabaena and Gonium), committed multicellular individuals (Pandorina and Eudorina), and committed, differentiated multicellular individuals (Pleodorina and Volvox). We suggest that a multidimensional approach to individuality in which researchers consider multiple criteria simultaneously may provide greater evolutionary insight via a more nuanced view that may better reflect the process of natural selection. 
Although the evolution of individuality is often thought of as a singular and dichotomous event, the volvocine algae show that multicellular organisms can differ in which aspects of individuality they exhibit and multiple criteria may be fulfilled at the same time. The evolutionary implications of interspecific variation in how criteria are satisfied for individuality are unclear; fulfilling some but not all criteria may have consequences yet to be appreciated. Does a certain kind of individuality inhibit or enhance subsequent evolutionary change or speciation rates, allow for greater reversibility, lower degrees of adaptation, or lower complexity of the organisms involved? What selection pressures lead to the various kinds of individuals in this lineage? These questions remain unanswered and future research should focus on the causes and consequences of variation in individuality.

\section{Acknowledgments}

The authors would like to thank Maureen O'Malley, Judie Bronstein, Patrick J. Ferris, Brad J. S. C. Olson, and anonymous reviewers for their helpful comments and discussion. We gratefully acknowledge the support of the National Aeronautics and Space Administration (NNX13AH41G), the National Institute of Health (GM084905), the National Science Foundation (MCB-1412395 and PHY11-25915) and the Gordon and Betty Moore Foundation (Award Num. 2919).

\section{Literature cited}

Aktipis, C. A., A. M. Boddy, G. Jansen, U. Hibner, M. E. Hochberg, C. C. Maley, and G. S. Wilkinson. 2015. "Cancer Across the Tree of Life: Cooperation and Cheating in Multicellularity." Philos. Trans. R. Soc. B Biol. Sci. 370: 20140219-20140219.

Arakaki, Y., H. Kawai-Toyooka, Y. Hamamura, T. Higashiyama, A. Noga, M. Hirono, B. J. S. C. Olson, and H. Nozaki. 2013. “The Simplest Integrated Multicellular Organism Unveiled.” PLoS One 8: e81641.

Barki, Y., D. Gateño, D. Graur, and B. Rinkevich. 2002. "Soft-Coral Natural Chimerism: A Window in Ontogeny Allows the Creation of Entities Comprised of Incongruous Parts." Mar. Ecol. Prog. Ser. 231: 91-99.

Becks, L., S. P. Ellner, L. E. Jones, and N. G. Hairston. 2010. "Reduction of Adaptive Genetic Diversity Radically Alters Eco-Evolutionary Community Dynamics." Ecol. Lett. 13: 989-97.

Bell, G. 1985. "The Origin and Evolution of Germ Cells as Illustrated by the Volvocales." In The Origin and Evolution of Sex, edited by H. O. Halvorson and A. Monroy, 221-256. New York: Alan R. Liss.

Bonner, J. T. 1998. “The Origins of Multicellularity.” Integr. Biol. Issues, Nerws, Rev. 1: 27-36.

Boraas, M. E., D. B. Seale, and J. E. Boxhorn. 1998. "Phagotrophy by a Flagellate Selects for Colonial Prey: A Possible Origin of Multicellularity.” Evol. Ecol. 12: 153-164.

Buss, L. W. 1987. The Evolution of Individuality. Princeton, NJ: Princeton University Press.

Buss, L. W. 1985. “The Uniqueness of the Individual Revisited.” In Population Biology and Evolution of Clonal Organisms, edited by J. B. Jackson, L. W. Buss, and R. E. Cook. New Haven, CT: Yale University Press.

Clarke, E. 2013. “The Multiple Realizability of Biological Individuals.” J. Philos. 110: 413-435.

Clarke, E. 2010. “The Problem of Biological Individuality." Biol. Theory 5: 312-325.

Coleman, A. W. 2012. “A Comparative Analysis of the Volvocaceae (Chlorophyta).” J. Phycol. 48: 491-513. 
Conrad, W. 1913. “Observations Sur Eudorina Elegans Ehrenberg.” Rec. Inst. Leo Errera 9: 321-343.

Crow, J. F. 1988. “The Importance of Recombination.” Pp. 56-73 in The Evolution of Sex: An Examination of Current Ideas. Edited by R. E. Michod and B. R. Levins. Sunderland, MA: Sinauer Associates.

Damuth, J., and I. L. Heisler. 1988. “Alternative Formulations of Multilevel Selection.” Biol. Philos. 3: 407-430.

Dawkins, R. 1982. The Extended Phenotype. Oxford: Oxford University Press.

De, S. 2011. "Somatic Mosaicism in Healthy Human Tissues." Trends Genet. 27: 217-223.

Folse, H. J., and J. Roughgarden. 2010. "What Is an Individual Organism? A Multilevel Selection Perspective.” Q. Rev. Biol. 85: 447-472.

Fulton, A. B. 1978. "Colonial Development in Pandorina morum: II. Colony Morphogenesis and Formation of the Extracellular Matrix." Dev. Biol. 251: 236-251.

Gardner, A., and A. Grafen. 2009. "Capturing the Superorganism: A Formal Theory of Group Adaptation.” J. Evol. Biol. 22: 659-671.

Gerhart, J., and M. Kirschner. 1997. Cells, Embryos, and Evolution: Toward a Cellular and Developmental Understanding of Phenotypic Variation and Evolutionary Adaptability. Malden, MA: Blackwell Science.

Gerisch, G. 1959. "Die Zelldifferenzierung bei Pleodorina Californica Shaw und Die Organisation Der Phytomonadinenkolonien." Arch. Für Protistenkd 104: 292-358.

Godfrey-Smith, P. 2011. "Darwinian Population and Transitions in Individuality." In The Major Transitions in Evolution Revisited. Edited by B. Calcott and K. Sterelny, 65-82. Cambridge, MA: MIT Press.

Godfrey-Smith, P. 2009. Darwinian Populations and Natural Selection. Oxford: Oxford University Press.

Goldstein, M. 1964. “Speciation and Mating Behavior in Eudorina.” J. Protozool. 11: 317-344.

Grosberg, R. K., and R. R. Strathmann. 1998. "One Cell, Two Cell, Red Cell, Blue Cell: The Persistence of a Unicellular Stage in Multicellular Life Histories.” Trends Ecol. Evol. 13: 112-116.

Grosberg, R. K., and R. R. Strathmann. 2007. "The Evolution of Multicellularity: A Minor Major Transition?” Annu. Rev. Ecol. Evol. Syst. 38: 621-654.

Hallmann, A. 2003. "Extracellular Matrix and Sex-Inducing Pheromone in Volvox." Int. Rev. Cytol. 227: 131-182.

Hallmann, A. 2006. “The Pherophorins: Common, Versatile Building Blocks in the Evolution of Extracellular Matrix Architecture in Volvocales.” Plant J. 45: 292-307.

Hanschen, E. R., T. N. Marriage, P. J. Ferris, T. Hamaji, A. Toyoda, A. Fujiyama, R. Neme, H. Noguchi, Y. Minakuchi, M. Suzuki, H. Kawai-Toyooka, D. R. Smith, V. Luria, A. Karger, M. W. Kirschner, H. Sparks, J. Anderson, R. Bakaric, P. M. Durand, R. E. Michod, H. Nozaki, and B. J. S. C. Olson. 2016. "The Gonium pectorale Genome Demostrates Co-Option of Cell Cycle Regulation During the Evolution of Multicellularity." Nat. Commun. 7: 11370.

Hanschen, E. R., D. E. Shelton, and R. E. Michod. 2015. "Evolutionary Transitions in Individuality and Recent Models in Multicellularity." In Evolutionary Transitions to Multicellular Life: Principles and Mechanisms. Edited by A. M. Nedelcu and I. Ruiz-Trillo, 165-188. Dordrecht, Netherlands: Springer.

Harper, R. A. 1912. "The Structure and Development of the Colony in Gonium." Trans. Am. Microsc. Soc. 31: 65-83. 
Harris, E. H. 2009. The Chlamydomonas Sourcebook. Volume 1. Second edition. Elsevier.

Heisler, I. L., and J. Damuth. 1987. "A Method for Analyzing Selection in Hierarchically Structured Populations." Am. Nat. 132: 582-602.

Herron, M. D., A. G. Desnitskiy, and R. E. Michod. 2010. "Evolution of Developmental Programs in Volvox (Chlorophyta)." J. Phycol. 46: 316-324.

Herron, M. D., J. D. Hackett, F. O. Aylward, and R. E. Michod. 2009. “Triassic Origin and Early Radiation of Multicellular Volvocine Algae.” Proc. Natl. Acad. Sci. USA 106: 3254-3258.

Herron, M. D., and R. E. Michod. 2008. "Evolution of Complexity in the Volvocine Algae: Transitions in Individuality Through Darwin's Eye." Evolution 62: 436-451.

Hull, D. 1980. "Individuality and Selection." Annu. Rev. Ecol. Syst. 11: 311-332.

Hull, D. L. 1976. "Are Species Really Individuals?” Syst. Zool. 25: 174.

Huxley, J. S. 1932. "Problems of Relative Growth." London: Methuen and Co.

Huxley, J. S. 1912. The Individual in the Animal Kingdom. Cambridge University Press, Cambridge, UK.

Isaka, N., H. Kawai-Toyooka, R. Matsuzaki, T. Nakada, and H. Nozaki. 2012. "Description of Two New Monoecious Species of Volvox Sect. Volvox (Volvocaceae, Chlorophyceae), Based on Comparative Morphology and Molecular Phylogeny of Cultured Material." J. Phycol. 48: 759-767.

Iwasa, K., and S. Murakami. 1968. "Palmelloid Formation of Chlamydomonas I. Palmelloid Induction by Organic Acids.” Physiol. Plant. 21: 1224-1233.

Iyengar, M. O. P., and T. V. Desikachary. 1981. Volvocales. New Dehli: Indian Council of Agricultural Research.

Janet, C. 1912. Le Volvox. Limoges, France: Imprimerie-Librairie Ducourtieux Et Gout.

Janzen, D. H. 1977. "What Are Dandelions and Aphids?" Am. Nat. 111: 586.

Jeuken, M. 1952. “The Concept 'Individual' in Biology." Acta Biotheor. 10: 57-86.

Kates, J. R., and R. F. Jones. 1964. "The Control of Gametic Differentiation in Liquid Cultures of Chlamydomonas." J. Cell. Comp. Physiol. 63: 157-164.

Khona, D. K., S. M. Shirolikar, K. K. Gawde, E. Hom, M. A. Deodhar, and J. S. D’Souza. 2016. "Characterization of Salt Stress-Induced Palmelloids in the Green Alga, Chlamydomonas reinhardtii." Algal Res. 16: 434-448.

Kirk, D. L. 2005. "A Twelve-Step Program for Evolving Multicellularity and a Division of Labor." BioEssays 27: 299-310.

Kirk, D. L. 1998. Volvox: Molecular-Genetic Origins of Multicellularity and Cellular Differentiation. Cambridge: Cambridge University Press.

Kirk, D. L., and M. M. Kirk. 1986. "Heat Shock Elicits Production of Sexual Inducer in Volvox." Science 231: 51-54.

Koufopanou, V., and G. Bell. 1993. "Soma and Germ: An Experimental Approach Using Volvox." Proc. R. Soc. London B Biol. Sci. 254: 107-113.

Legere, A., and S. Payette. 1981. "Ecology of a Black Spruce (Picea mariana) Clonal Population in the Hemiarctic Zone, Northern Quebec: Population Dynamics and Spatial Development." Artic Alp. Res. 13: 261-276.

Leliaert, F., D. R. Smith, H. Moreau, M. D. Herron, H. Verbruggen, C. F. Delwiche, and O. De Clerck. 2012. "Phylogeny and Molecular Evolution of the Green Algae." CRC. Crit. Rev. Plant Sci. 31: 1-46. 
Lewontin, R. C. 1970. "The Units of Selection.” Annu. Rev. Ecol. Syst. 1: 1-18.

Lloyd, E., and S. J. Gould. 1993. "Species Selection on Variability." Proc. Natl. Acad. Sci. USA 90: 595-599.

Lurling, M., and W. Beekman. 2006. "Palmelloids Formation in Chlamydomonas reinhardtii: Defence Against Rotifer Predators?” Ann. Limnol.-Int. J. Limnol. 42: 65-72.

Maynard Smith, J. 1988. "Evolutionary Progress and the Levels of Selection." In Evolutionary Progress. Edited by M. Nitecki. Chicago: University of Chicago Press.

Maynard Smith, J., and E. Szathmáry. 1995. The Major Transitions in Evolution. Oxford: Oxford University Press.

Meneses, I., B. Santelices, and P. Sanchez. 1999. "Growth-Related Intraclonal Genetic Changes in Gracilaria chilensis (Gracilariales: Rhodophyta).” Mar. Biol. 135: 391-397.

Michod, R. E. 1996. "Cooperation and Conflict in the Evolution of Individuality. II. Conflict Mediation.” Proc. Biol. Sci. 263: 813-822.

Michod, R. E. 1999. Darwinian Dynamics, Evolutionary Transitions in Fitness and Individuality. Princeton, NJ: Princeton University Press.

Michod, R. E. 2007. "Evolution of Individuality During the Transition From Unicellular to Multicellular Life.” Proc. Natl. Acad. Sci. USA 104: 8613-8618.

Michod, R. E. 2005. "On the Transfer of Fitness From the Cell to the Multicellular Organism.” Biol. Philos. 20: 967-987.

Michod, R. E. 2006. “The Group Covariance Effect and Fitness Trade-Offs During Evolutionary Transitions in Individuality." Proc. Natl. Acad. Sci. USA 103: 9113-9117.

Michod, R. E., and D. Roze. 1997. "Transitions in Individuality." Proc. R. Soc. London B, Biol. Sci. 264: 853-857.

Michod, R. E., Y. Viossat, C. A. Solari, M. Hurand, and A. M. Nedelcu. 2006. "Life-History Evolution and the Origin of Multicellularity." J. Theor. Biol. 239: 257-272.

Mishler, B. D., and R. N. Brandon. 1987. "Individuality, Pluralism, and the Phylogenetic Species Concept.” Biol. Philos. 2: 397-414.

Nakamura, K., D. F. Bray, and E. B. Wagenaar. 1978. "Ultrastructure of a Palmelloid-Forming Strain of Chlamydomonas eugametos." Can. J. Bot. 56: 2348-2356.

Nakamura, K., D. F. Bray, and E. B. Wagenaar. 1975. "Ultrastructure of Chlamydomonas eugametos Palmelloids Induced by Chloroplatinic Acid Treatment.” J. Bacteriol. 121: 338-343.

Nozaki, H. 1983. “Morphology and Taxonomy of Two Species of Astrephomene in Japan." Japanese J. Phycol. 58: 345-352.

Nozaki, H., F. D. Ott, and A. W. Coleman. 2006. "Morphology, Molecular Phylogeny and Taxonomy of Two New Species of Pleodorina (Volvoceae, Chlorophyceae).” J. Phycol. 42: 1072-1080.

Okasha, S. 2006. Evolution and the Levels of Selection. Oxford: Clarendon Press.

Peabody, R. B., D. C. Peabody, and K. M. Sicard. 2000. "A Genetic Mosaic in the Fruiting Stage of Armillaria gallica." Fungal Genet. Biol. 29: 72-80.

Pepper, J. W., and M. D. Herron. 2008. “Does Biology Need an Organism Concept?” Biol. Rev. Camb. Philos. Soc. 83: 621-7.

Pineda-Krch, M., and K. Lehtilä. 2004. "Costs and Benefits of Genetic Heterogeneity Within Organisms.” J. Evol. Biol. 17: 1167-1177. 
Pocock, M. A. 1933a. "Volvox and Associated Algae From Kimberley." Ann. South African Museum 16: 473-522.

Pocock, M. A. 1933b. "Volvox in South Africa." Ann. South African Museum 16: 523-658.

Powers, J. 1908. "Further Studies in Volvox, With Descriptions of Three New Species." Trans. Am. Microsc. Soc. 28: 141-175.

Prochnik, S. E., J. Umen, A. M. Nedelcu, A. Hallmann, S. M. Miller, I. Nishii, P. J. Ferris, A. Kuo, T. Mitros, L. K. Fritz-Laylin, U. Hellsten, J. Chapman, O. Simakov, S. A. Rensing, A. Terry, J. Pangilinan, v. Kapitonov, J. Jurka, A. Salamov, H. Shapiro, J. Schmutz, J. Grimwood, E. Lindquist, S. Lucas, I. V. Grigoriev, R. Schmitt, D. L. Kirk, and D. S. Rokhsar. 2010. "Genomic Analysis of Organismal Complexity in the Multicellular Green Alga Volvox carteri." Science 329: 223-6.

Queller, D. C., and J. E. Strassmann. 2009. "Beyond Society: The Evolution of Organismality.” Philos. Trans. R. Soc. London Ser. B, Biol. Sci. 364: 3143-3155.

Ratcliff, W. C., M. D. Herron, K. Howell, J. T. Pentz, F. Rosenzweig, and M. Travisano. 2013. "Experimental Evolution of an Alternating Uni- and Multicellular Life Cycle in Chlamydomonas reinhardtii." Nat. Commun. 4: 2742.

Rinkevich, B., and I. L. Weissman. 1987. "A Long-Term Study on Fused Subclones in the Ascidian Botryllus schlosseri: The Resorption Phenomenon (Protochordata: Tunicata).” J. Zool. 213: 717733.

Sager, R., and S. Granick. 1954. "Nutritional Control of Sexuality in Chlamydomonas reinhardtii." J. Gen. Physiol. 37: 729-742.

Santelices, B. 1999. "How Many Kinds of Individual Are There?” Trends Ecol. Evol. 14: 152-155.

Santelices, B., J. A. Correa, D. Aedo, V. Flores, M. Hormazábal, and P. Sánchez. 1999. “Convergent Biological Processes in Coalescing Rhodophyta." J. Phycol. 35: 1127-1149.

Santelices, B., and D. Varela. 1993. "Intra-Clonal Variation in Red Seaweed Gracilaria chilensis." Mar. Biol. 552: 543-552.

Sathe, S., and P. M. Durand. 2015. "Cellular Aggregation in Chlamydomonas (Chlorophyceae) Is Chimaeric and Depends on Traits Like Cell Size and Motility." Eur. J. Phycol. 262: 1-10.

Shaw, W. R. 1894. "Pleodorina, a New Genus of the Volvocineæ." Bot. Gaz. 19: 279-283.

Shelton, D. E., and R. E. Michod. 2014. "Group Selection and Group Adaptation During a Major Evolutionary Transition: Insights From the Evolution of Multicellularity in the Volvocine Algae." Biol. Theory 9: 452-469.

Shelton, D. E., and R. E. Michod. 2009. "Philosophical Foundations for the Hierarchy of Life." Biol. Philos. 25: 391-403.

Short, M. B., C. A. Solari, S. Ganguly, T. R. Powers, J. O. Kessler, and R. E. Goldstein. 2006. "Flows Driven by Flagella of Multicellular Organisms Enhance Long-Range Molecular Transport." Proc. Natl. Acad. Sci. USA 103: 8315-8319.

Simpson, C. 2012. “The Evolutionary History of Division of Labour.” Proc. R. Soc. B Biol. Sci. 279: 116-121.

Simpson, G. G., C. S. Pittendrigh, and L. H. Tiffany. 1957. Life: An Introduction to Biology. New York: Harcourt, Brace, and Co.

Smith, G. M. 1944. "A Comparative Study of the Species of Volvox." Trans. Am. Microsc. Soc. 63: 265-310. 
Sober, E., and D. S. Wilson. 1994. "A Critical Review of Philosophical Work on the Units of Selection Problem.” Philos. Sci. 61: 534-555.

Solari, C. A., S. Ganguly, J. O. Kessler, R. E. Michod, and R. E. Goldstein. 2006a. "Multicellularity and the Functional Interdependence of Motility and Molecular Transport." Proc. Natl. Acad. Sci. USA 103: 1353-1358.

Solari, C. A., J. O. Kessler, and R. E. Michod. 2006b. "A Hydrodynamics Approach to the Evolution of Multicellularity: Flagellar Motility and Germ-Soma Differentiation in Volvocalean Green Algae." Am. Nat. 167: 537-554.

Sommer, U., and Z. Maciej Gliwicz. 1986. "Long Range Vertical Migration of Volvox in Tropical Lake Cahora Bassa (Mozambique).” Limnol. Oceanogr. 31: 650-653.

Sommerfeldt, A. D., J. D. D. Bishop, and C. A. Wood. 2003. "Intraclonal Genetic Variation: Ecological and Evolutionary Aspects.” Biol. J. Linn. Soc. 79: 183-192.

Starr, R. C. 1970. "Control of Differentiation in Volvox.” Dev. Biol. Suppl. 4: 59-100.

Starr, R. C. 1955. "Sexuality in Gonium sociale (Dujardin) Warming.” J. Tennessee Acad. Sci. 30: 90-93.

Starr, R. C. 1969. "Structure, Reproduction and Differentiation in Volvox carteri f. nagariensis iyengar, Strains HK9 \& 10.” Arch. Für Protistenkd. 111: 204-222.

Stein, J. R. 1965. "On Cytoplasmic Strands in Gonium pectorale (Volvocales).” J. Phycol. 1: 1-5.

Stenlid, J. 2000. "Variation With and Without Sex in Mycorrhizal Fungi." Oikos 90: 609-611.

Sterelny, K., and P. E. Griffiths. 1999. Sex and Death: An Introduction to Philosophy of Biology. Chicago: University of Chicago Press.

Stoner, D. S., B. Rinkevich, and I. L. Weissman. 1999. "Heritable Germ and Somatic Cell Lineage Competitions in Chimeric Colonial Protochordates." Proc. Natl. Acad. Sci. USA 96: 9148-9153.

Sumper, M., and A. Hallmann. 1998. "Biochemistry of the Extracellular Matrix of Volvox." Int. Rev. Cytol. 180: 51-85.

Tauber, A. I. 1991. Organism and the Origins of Self. Dordrecht, Netherlands: Kluwer Academic Publishers.

van Leeuwenhoek, A. 1700. "Part of a Letter From Mr Antony van Leeuwenhoek, Concerning the Worms in Sheeps Livers, Gnats, and Animalcula in the Excrements of Frogs." Philos. Trans. $R$. Soc. London 22: 509-518.

Viktora, M., R. A. Savidge, and O. P. Rajora. 2011. "Clonal and Nonclonal Genetic Structure of Subarctic Black Spruce (Picea mariana) Populations in Yukon Territory.” Botany 89: 133-140.

Vrba, E. S. 1984. "What Is Species Selection?” Syst. Zool. 33: 318-328.

Weismann, A. 1885. "The Continuity of the Germ-Plasm as the Foundation of a Theory of Heredity." Essays Upon Hered. Kindred Biol. Probl. 1: 163-254.

Weismann, A. 1904. The Evolution Theory. Volume 1. London: Edward Arnold.

Whitham, T. G., and C. N. Slobodchikoff. 1981. "Evolution by Individuals, Plant-Herbivore Interactions, and Mosaics of Genetic Variability: The Adaptive Significance of Somatic Mutations in Plants." Oecologia 49: 287-292.

Wilson, D. S. 1975. "A Theory of Group Selection.” Proc. Natl. Acad. Sci. USA 72: 143-146.

Wimsatt, W. C. 1997. "Aggregativity: Reductive Heuristics for Finding Emergence.” In Proceedings of the 1996 Biennial Meetings of the Philosophy of Science Association. Part II: Symposia Papers. Philosophy of Science 64 (supplement). 
(C) 2017 Author(s)

This is an open-access article distributed under the terms of the Creative Commons AttributionNonCommercial-NoDerivatives 4.0 International license, which permits anyone to download, copy, distribute, or display the full text without asking for permission, provided that the creator(s) are given full credit, no derivative works are created, and the work is not used for commercial purposes.

ISSN 2475-3025 